\title{
Effect of bracing on respiratory mechanics in mild idiopathic scoliosis
}

\author{
J DECLAN KENNEDY, COLIN F ROBERTSON, IRENE HUDSON, \\ PETER D PHELAN
}

From the Professorial Department of Thoracic Medicine, Royal Children's Hospital, and the Department of Paediatrics, University of Melbourne, Parkville, Victoria, Australia

\begin{abstract}
The use of a corrective orthopaedic brace is an established form of management for patients with progressive idiopathic scoliosis. Thirteen patients with mild idiopathic scoliosis were studied with and without the corrective brace applied. Lung volumes and the pattern of chest wall and abdominal movement were measured during quiet breathing. Transdiaphragmatic pressures were measured in six of the patients and upper ribcage movement in seven patients. Application of the brace resulted in a significant reduction in vital capacity (14\%), functional residual capacity $(22 \%)$, and total lung capacity (12\%). There was no effect on respiratory rate or minute volume. In the erect position the pattern of chest wall movement was altered with a reduction in lower ribcage movement of $46 \%$ and abdominal wall of $39 \%$ and an increase in upper ribcage movement of $43 \%$. These changes were greater in the supine position. There was at least a twofold increase in end inspiratory and end expiratory gastric pressures during tidal breathing, but oesophageal pressures were not affected by the brace. Transdiaphragmatic pressures showed a similar twofold increase, which implies a substantial increase in the work of breathing. In view of the doubts concerning the influence of bracing on the natural history of idiopathic scoliosis and the substantial functional effect of bracing on the respiratory system, it is suggested that the current practice of bracing in this condition needs to be reviewed.
\end{abstract}

\section{Introduction}

Scoliosis is the most common abnormality of the thoracic cage. 'Two out of every 1000 adolescents have a curve of 20 degrees or more, for which treatment is recommended. ${ }^{2}$

Although the condition has afflicted man from the earliest times, the natural history remains poorly defined and treatment remains controversial. ${ }^{34}$ Ambrose Paré in 1582 used iron corsets in an attempt to prevent progression of the curve, but modern bracing treatment began with the introduction of the Milwaukee brace in the 1950s. ${ }^{5}$ In 1975 the Boston bracing system was described by Hall et al. ${ }^{6}$ These braces are now widely accepted in the non-operative treatment of idiopathic scoliosis, though the effectiveness of bracing in the management of idiopathic

Address for reprint requests: Dr C F Robertson, Professorial Department of Thoracic Medicine, Royal Children's Hospital, Parkville, Victoria 3052, Australia.

Accepted 31 March 1989 scoliosis has been debated among orthopaedic surgeons. $^{34}$

Despite the use of these restrictive braces for over 400 years, their functional effects on respiratory mechanics have been little studied. Glucker ${ }^{7}$ showed a fall in vital capacity (VC) of $29 \%$ in seven patients treated with the Milwaukee brace, but Sevastikoglou ${ }^{8}$ found that the same brace did not alter VC significantly in 26 patients with idiopathic scoliosis. We recently studied the effects of orthopaedic bracing (Milwaukee and Boston) on lung volumes in 33 adolescents with idiopathic thoracic scoliosis and found that the mean reduction in functional residual capacity (FRC) was $26 \%$ and six subjects showed a reduction of more than $40 \% .{ }^{9}$

We postulated that the cause of this reduction in lung volume was due to restriction of the chest wall by the brace and compression of abdominal contents into the thorax. The aim of this study was to evaluate the disturbance in respiratory mechanics associated with bracing further by measuring chest wall movement and pleural and gastric pressure changes. 


\section{Methods}

We studied 13 adolescents, 12 girls and one boy, with idiopathic scoliosis of the thoracic spine, selecting them by approaching the first 13 patients of the previous study group. ${ }^{9}$ All were patients of the orthopaedic bracing programme at the Royal Children's Hospital. Eight used a Boston brace and five a Milwaukee brace. Their mean age was 13.5 years and the mean thoracic Cobb angle 29 degrees (table 1). The duration of bracing ranged from one month to six years. None of the patients had any cardiopulmonary symptoms at the time of testing.

The subjects were inexperienced in respiratory function testing. All had a physical examination and answered a questionnaire to delineate any respiratory or cardiac symptoms, family history of chest disease, and use of medication.

Lung volumes were measured with the brace off and on in the sitting erect posture by body plethysmography (Jaeger Bodyscreen 2) and expressed as percentages of predicted values. ${ }^{10}$ The order of testing - that is, brace on or off first-was randomised. All values were corrected to BTPS. Non-deformed height was estimated from armspan measurements. In our laboratory armspan:height ratios estimated from 2368 measurements of 8-18 year olds are close to unity: $0.999+0.023$ for girls and $1.006+0.022$ for boys. ${ }^{.1}$

Flow at the mouth was measured with a No 3 Fleisch pneumotachometer (Fleisch, Lausanne, Switzerland) connected to a Validyne differential transducer and a Validyne carrier-amplifier (Validyne Co, Northridge, California). The signal was integrated to give volume. Calibration was carried out with a 3 litre calibration syringe (Vancumed, Ventura, California).

An induction coil plethysmograph (Respitrace) was used to measure chest wall movement. The thoracic Respitrace band was placed around the subject's chest, the mid axillary point of the 9th ribs being used as a landmark. The centre of the band was placed over these points and fastened in front. The abdominal Respitrace band was placed over the mid abdomen with the anterior superior iliac spines as landmarks. The centre of the band was fixed over these points and fastened in front. Using the same procedure in all subjects, we measured the deflection of the abdominal and ribcage bands during quiet tidal breathing with the brace off while they were sitting erect. The deflection magnitude per breath was measured over one minute and the mean value taken. To this mean deflection per tidal breath a value of $100 \%$ was ascribed. We measured the increase or decrease in Respitrace band deflection associated with the change in posture or brace wearing against this standard.

In seven children the change in anteroposterior diameter in the upper thorax was measured by attaching a single pair of magnetometers to the right 2 nd intercostal space, $2.5 \mathrm{~cm}$ from the lateral sternal margin. They were calibrated and found to be linear over the range of ribcage excursion. The mean deflection per tidal breath while they were sitting erect was also estimated over one minute and ascribed a value of $100 \%$. The increase or decrease in upper ribcage movement associated with change in posture or application of the brace was measured against the "brace off sitting erect" value.

In six of the 13 subjects gastric and pleural pressures were measured by means of a double balloon catheter system. ${ }^{12}$ The gastric balloon was $5 \mathrm{~cm}$ in length and the oesophageal balloon $10 \mathrm{~cm}$. Both balloons were 1.8 $\mathrm{cm}$ in diameter and each was connected to a separate pressure transducer (Stratham Instruments, Hato Rey, Pennsylvania) that had been calibrated with a U

Table 1 Characteristics of the patients

\begin{tabular}{|c|c|c|c|c|c|c|c|c|}
\hline \multirow[b]{2}{*}{ Subject No } & \multirow[b]{2}{*}{ Age (y) } & \multirow[b]{2}{*}{ Sex } & \multirow[b]{2}{*}{ Brace } & \multirow{2}{*}{$\begin{array}{l}\text { Cobb } \\
\text { angle }\left({ }^{\circ}\right)\end{array}$} & \multirow{2}{*}{$\begin{array}{l}\text { Armspan } \\
(\mathrm{cm})\end{array}$} & $V C$ & $F R C$ & $T L C$ \\
\hline & & & & & & \multicolumn{3}{|c|}{ (\% pred,,$^{10}$ without brace) } \\
\hline $\begin{array}{c}1^{*} \\
2^{*} \\
3^{*} \\
4^{*} \\
5^{*} \\
6^{*} \\
7 \\
8 \\
9 \\
10 \\
11 \\
12 \\
13\end{array}$ & $\begin{array}{l}13.4 \\
12 \\
13.9 \\
14.8 \\
14.0 \\
15.0 \\
13.0 \\
15.0 \\
13.0 \\
13.0 \\
13.0 \\
14.0 \\
11.0\end{array}$ & $\begin{array}{l}\text { F } \\
\text { F } \\
M \\
\text { F } \\
F \\
F \\
F \\
F \\
F \\
F \\
F \\
F \\
F\end{array}$ & $\begin{array}{l}\text { Boston } \\
\text { Milwaukee } \\
\text { Milwaukee } \\
\text { Boston } \\
\text { Boston } \\
\text { Boston } \\
\text { Milwaukee } \\
\text { Boston } \\
\text { Milwaukee } \\
\text { Boston } \\
\text { Boston } \\
\text { Boston } \\
\text { Milwaukee }\end{array}$ & $\begin{array}{l}18 \\
35 \\
40 \\
12 \\
25 \\
26 \\
35 \\
30 \\
49 \\
23 \\
32 \\
30 \\
26\end{array}$ & $\begin{array}{l}168.6 \\
155.7 \\
184.0 \\
168.0 \\
178.5 \\
164.0 \\
146.6 \\
161.0 \\
154.0 \\
172.9 \\
163.0 \\
154.0 \\
163.5\end{array}$ & $\begin{array}{r}87 \\
85 \\
89 \\
95 \\
83 \\
98 \\
93 \\
84 \\
58 \\
67 \\
76 \\
108 \\
72\end{array}$ & $\begin{array}{r}99 \\
105 \\
88 \\
131 \\
87 \\
104 \\
87 \\
114 \\
77 \\
90 \\
109 \\
109 \\
96\end{array}$ & $\begin{array}{r}87 \\
93 \\
83 \\
106 \\
83 \\
98 \\
94 \\
96 \\
69 \\
80 \\
82 \\
113 \\
94\end{array}$ \\
\hline $\begin{array}{l}\text { Mean } \\
\text { SEM }\end{array}$ & $\begin{array}{r}13.4 \\
0.3\end{array}$ & & & $\begin{array}{c}29 \cdot 0 \\
2.63\end{array}$ & $\begin{array}{r}164.5 \\
2.9\end{array}$ & $\begin{array}{l}84 \\
3.74\end{array}$ & $\begin{array}{l}99 \\
4 \cdot 0\end{array}$ & $\begin{array}{l}90 \\
3 \cdot 2\end{array}$ \\
\hline
\end{tabular}

*Balloons passed. VC - vital capacity; FRC — functional residual capacity; TLC—-total lung capacity. 
tube water manometer. The pressure-volume characteristics of the balloons were estimated and found to be flat within a volume range of $0.3-4.0 \mathrm{ml}$. The static accuracy of the balloons was checked by the method of Beardsmore et al. ${ }^{13}$ For assessment of dynamic balloon accuracy, the subjects performed static voluntary efforts with the glottis open against a closed mouthpiece, and oesophageal (Poes) and mouth (Pmouth) pressures were recorded ${ }^{14}$ and accepted if the Poes: Pmouth ratio was greater than 0.9.

Placement of the balloon system was carried out in the following manner. The subject had the nasal passages anaesthetised by sniffing $2 \%$ xylocaine. The balloons were then passed at least $65 \mathrm{~cm}$ from the nares into the stomach. The patient carried out a Valsalva manoeuvre to empty the balloons, and $1.0 \mathrm{ml}$ of air was then injected into the gastric and $0.5 \mathrm{ml}$ into the oesophageal balloon. The position of the balloons in the stomach was confirmed by means of positive deflections when the subject sniffed. The tube was then gently withdrawn until the first recording of a negative deflection from the oesophageal balloon during a sniff. The balloon was then withdrawn a further $10 \mathrm{~cm}$ to ensure that all the oesophageal balloon lay in the lower or mid oesophagus. The final position was further checked with a series of sniffs giving substantial positive deflections from the gastric balloon and negative deflections from the oesophageal balloon. Transdiaphragmatic pressure (Pdi) was derived by the electrical summation of the oesophageal and gastric pressure (Pgas) signals $(\mathbf{P d i}=$ Pgas - Poes).

The subjects were instructed to breathe quietly through the pneumotachograph while sitting erect for about five minutes. Pgas, Poes, and Pdi; minute ventilation; and abdominal and ribcage movements were recorded. Subjects maintained the erect posture by sitting or kneeling in an ergonomic chair in which the weight was shared between knees and buttocks. It is a comfortable means of maintaining relatively constant erect posture. The subject then lay supine and again breathed quietly for a further five minutes while the above recordings were repeated. These two steps, tidal breathing while sitting erect and while supine, were repeated with the brace on if the individual had

Table 2 Mean (SEM) lung volumes with and without brace in 13 patients

\begin{tabular}{|c|c|c|c|c|c|c|}
\hline \multirow[b]{2}{*}{$\begin{array}{l}\text { VC } \\
\text { FRC } \\
\text { TLC }\end{array}$} & \multicolumn{2}{|c|}{ Brace off $(l)$} & \multicolumn{2}{|c|}{ Brace on (l) } & \multirow{2}{*}{$\begin{array}{l}\begin{array}{l}\text { Mean \% } \\
\text { change }\end{array} \\
14 \cdot 3^{*} \\
21 \cdot 7^{*} \\
11 \cdot 9^{*}\end{array}$} & \multirow{2}{*}{$\begin{array}{l}95 \text { th centile } \\
(\%) \dagger \\
3.9 \\
9.8 \\
5.2\end{array}$} \\
\hline & $\begin{array}{l}2 \cdot 8 \\
2 \cdot 3 \\
4 \cdot 2\end{array}$ & $\begin{array}{l}(0 \cdot 2) \\
(0 \cdot 1) \\
(0 \cdot 2)\end{array}$ & $\begin{array}{l}2.4 \\
1.8 \\
3.7\end{array}$ & $\begin{array}{l}(0 \cdot 2) \\
(0 \cdot 1) \\
(0 \cdot 2)\end{array}$ & & \\
\hline
\end{tabular}

$* 0<0.01$.

†95th centile of coefficient of variation of change in lung volumes with time (within and between days) in normal subjects in our laboratory. Abbreviations as in table 1 . been randomly allocated to "brace off" testing first, and vice versa. The last minute of each five minute recording period was used for analysis; the results were expressed as mean values. All results were recorded on an eight channel paper record (Hewlett/Packard 88248) and a Teac MR 30 eight channel Data tape recorder.

The study was approved by the hospital ethics committee and informed consent was obtained from subjects and parents.

\section{STATISTICAL ANALYSIS}

The effect of bracing on lung volumes and pressures was assessed by the Wilcoxon signed rank test and the paired $t$ test. Change in lung volumes was compared with the 95th centile for the coefficient of variation for lung volumes in normal subjects for our laboratory. Analysis of variance was used to determine the effect of different types of braces. Statistical significance was set at the $5 \%$ level.

\section{Results}

The physical profile of the subjects is shown in table 1 . The group showed a mild reduction in vital capacity (VC) $\%$ predicted $(84 \%)$ with the brace off. Thoracic gas volume at functional residual capacity (FRC) and total lung capacity (TLC) were normal with the brace off. With application of the brace there was a significant reduction in all lung volumes-VC, FRC, and TLC (table 2).

In neither the sitting erect nor the supine posture did wearing the brace alter minute ventilation or respiratory rate (table 3 ). When subjects were sitting erect

Table 3 Ventilatory patterns in patients with and without brace (mean (SEM) values)

\begin{tabular}{|c|c|c|c|c|}
\hline & $\begin{array}{l}\text { No of } \\
\text { subjects }\end{array}$ & Brace off & Brace on & $p^{*}$ \\
\hline $\begin{array}{l}\text { ERECT: } \\
\dot{V} \text { VE }(1 / \min )\end{array}$ & 13 & $10 \cdot 5(0.7)$ & $10 \cdot 1 \quad(0.7)$ & NS \\
\hline $\begin{array}{l}\text { Respiratory rate } \\
\text { (beats/min) }\end{array}$ & 13 & $20 \cdot 3(1 \cdot 3)$ & $21 \cdot 2 \quad(1.4)$ & NS \\
\hline $\begin{array}{l}\text { Lower ribcage } \\
\text { movement (\%) }\end{array}$ & 13 & $100 \cdot 0(0 \cdot 0)$ & $53 \cdot 8(12 \cdot 1)$ & 0.012 \\
\hline $\begin{array}{l}\text { (\%) } \\
\text { Upper ribcage }\end{array}$ & 13 & $100 \cdot 0(0.0)$ & $60 \cdot 8(18 \cdot 2)$ & 0.036 \\
\hline movement (\%) & 7 & $100 \cdot 0(0.0)$ & $142.9(10 \cdot 3)$ & 0.013 \\
\hline $\begin{array}{l}\text { SUPINE: } \\
\text { VE (1/min) }\end{array}$ & 13 & $9.8(0.6)$ & $9.6(0.7)$ & NS \\
\hline $\begin{array}{l}\text { Respiratory rate } \\
\text { (breaths/min) }\end{array}$ & 13 & $17 \cdot 9(1 \cdot 5)$ & $20.9 \quad(1.5)$ & NS \\
\hline $\begin{array}{l}\text { Lower ribcage } \\
\text { movement (\%) }\end{array}$ & 13 & $81 \cdot 8(5 \cdot 2)$ & $50 \cdot 5 \quad(9 \cdot 6)$ & 0.025 \\
\hline $\begin{array}{l}\text { Abdominal movement } \\
\text { (\%) }\end{array}$ & 13 & $220 \quad(43.4)$ & $84 \cdot 6(19 \cdot 4)$ & 0.003 \\
\hline $\begin{array}{l}\text { Upper nbcage } \\
\text { movement (\%) }\end{array}$ & 7 & $92 \quad(24 \cdot 2)$ & $180.0(28.9)$ & 0.03 \\
\hline
\end{tabular}

$\dot{V}_{E}$-Minute ventilation.

* Comparison of measurements made with the brace on and off. 
there was a substantial effect of bracing on chest wall movement: lower ribcage movement was reduced by $46 \%$ and abdominal movement by $39 \%$. In the seven subjects who had magnetometers applied to the upper thorax there was an increase of $42.9 \%$ in respiratory excursion with the brace on, suggesting accessory muscle recruitment (table 3 ).

In the supine posture the restrictive effect of the brace on chest wall movement was also seen. Lower ribcage excursion was reduced by $38 \%$ and abdominal wall movement by $62 \%$. Magnetometers on the upper thorax showed an increase in movement of $95 \%$ (table 3).

In the six subjects whose oesophageal and gastric pressures were measured application of the brace caused at least a twofold increase in end inspiratory and end expiratory gastric pressure in both the sitting erect and the supine posture $(p<0.001)$; Poes was unaltered (table 4 and figure). Transdiaphragmatic pressures during tidal breathing were considerably raised with the brace on at both end inspiration and end expiration. There was a threefold increase in the respiratory swing in gastric pressure $(p<0.006)$ and a twofold increase in the swing in transdiaphragmatic pressure $(\mathrm{p}<0.005)$.

There was no difference between the Boston and the Milwaukee brace for lung volume or for chest wall and abdominal movement.

\section{Discussion}

There is widespread acceptance of the use of braces in the treatment of idiopathic scoliosis. In recent years many countries have introduced large scale screening programmes, ${ }^{15}$ but the effect of bracing in altering the natural history of idiopathic scoliosis is questionable. ${ }^{3}$

Table 4 Mean (SEM) values for transdiaphragmatic pressure and its components in six patients with and without brace

\begin{tabular}{|c|c|c|c|c|}
\hline & \multicolumn{2}{|l|}{ Seated } & \multicolumn{2}{|l|}{ Lying supine } \\
\hline & Brace off & Brace on & Brace off & Brace on \\
\hline $\begin{array}{l}\text { Poes (cm } \\
\text { Min } \\
\text { Max } \\
\text { Swing }\end{array}$ & $\begin{array}{l}\left.\mathrm{H}_{2} \mathrm{O}\right) \\
-3.8(1.6) \\
-10.0(2.2) \\
6.2(1.0)\end{array}$ & $\begin{array}{r}-1.0(1.0) \\
-8.4(1.3) \\
7.4(0.7)\end{array}$ & $\begin{array}{r}2.6(0.9) \\
-\quad 5.4(0.6) \\
7.9(0.7)\end{array}$ & $\begin{array}{r}2.9(1 \cdot 1) \\
-\quad 6.0(1.3) \\
8.8(0 \cdot 6)\end{array}$ \\
\hline $\begin{array}{l}\text { Pgas (cm } \\
\text { Min } \\
\text { Max } \\
\text { Swing }\end{array}$ & $\begin{aligned} &\left.\mathrm{H}_{2} \mathrm{O}\right) \\
& 8 \cdot 6(0 \cdot 8) \\
& 12 \cdot 3(0 \cdot 7) \\
& 3 \cdot 7(0 \cdot 8)\end{aligned}$ & $\begin{array}{l}18.0(2.2) \\
35 \cdot 2(2 \cdot 7) \\
17(1 \cdot 8)\end{array}$ & $\begin{array}{l}3.9(0.6) \\
8.9(0.4) \\
5.0(0.5)\end{array}$ & $\begin{array}{r}8 \cdot 7(1 \cdot 1) \\
25 \cdot 4(2 \cdot 1) \\
16 \cdot 7(2 \cdot 1)\end{array}$ \\
\hline $\begin{array}{l}\text { Pdi (cm H } \\
\text { Min } \\
\text { Max } \\
\text { Swing }\end{array}$ & $\begin{array}{l}\left.\mathrm{H}_{2} \mathrm{O}\right) \\
13 \cdot 1(2 \cdot 1) \\
23 \cdot 0(2 \cdot 6) \\
9.9(0.8)\end{array}$ & $\begin{array}{l}19.5(2.3) \\
44.9(2.9) \\
25.4(2.3)\end{array}$ & $\begin{array}{r}2.3(0.7) \\
14.8(0.8) \\
12.6(0.8)\end{array}$ & $\begin{array}{r}6.4(2.0) \\
31.8(3.2) \\
25.4(2.5)\end{array}$ \\
\hline
\end{tabular}

Poes-oesophageal pressure; Pgas-gastric pressure; Pdi-transdiaphragmatic pressure; Min-end expiration; Max-end inspiration during tidal breathing.

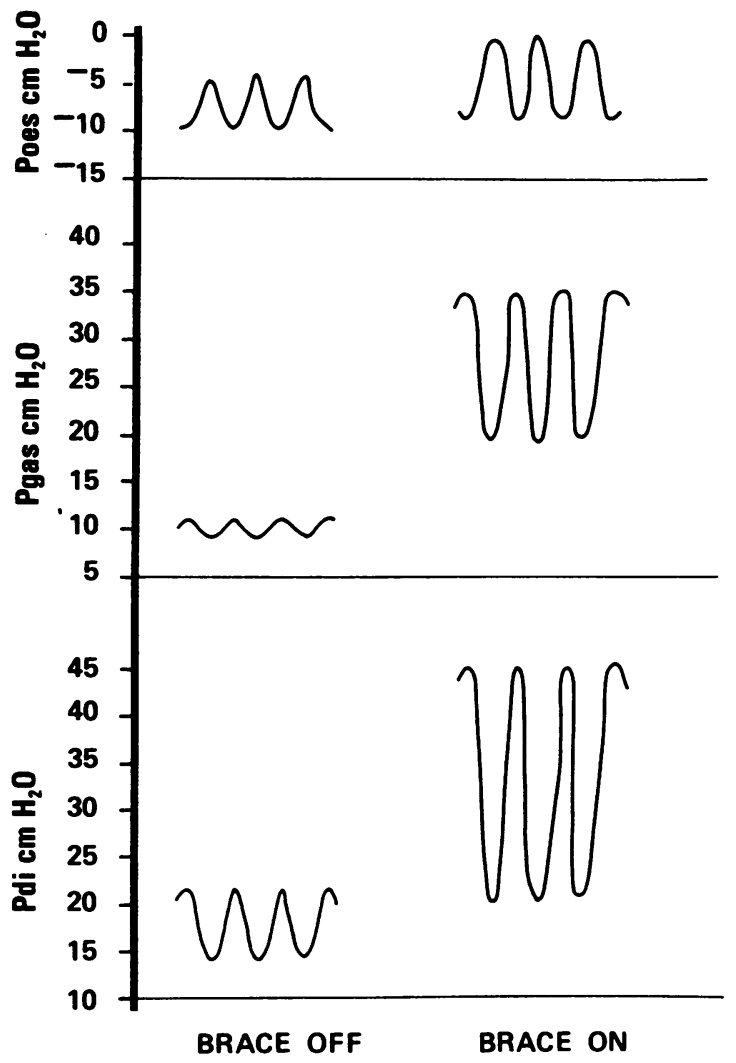

Diagrammatic representation of oesophageal (Poes), gastric (Pgas), and transdiaphragmatic (Pdi) pressure changes during tidal breathing with and without brace.

Long term reviews of both Boston and Milwaukee braces suggest that the mean effect of bracing is to produce a curve that is only a few degrees better than the original..$^{16-18}$ Concerns about the development of cardiorespiratory failure in idiopathic scoliosis have recently been alleviated by Branthwaite, who found that the risk is minimal in those whose scoliosis develops after the age of 11 years. ${ }^{19}$ Despite the general use of braces in idiopathic scoliosis for over 30 years, their effects other than on progression of the curve has remained largely unstudied. We have now shown that chest wall mechanics are profoundly affected by bracing.

For the brace to achieve derotation of the thoracic curve it is important that the associated lumbar lordosis is corrected. ${ }^{20}$ All braces, both of Boston and of Milwaukee design, achieve this by being tightly fitted around the abdomen. This restriction increases intra-abdominal pressure, which affects both the abdominal viscera and the normal pattern of chest wall mechanics. 
There is disagreement on the effect of bracing on lung volumes. Sevastikoglou ${ }^{8}$ studied 26 patients with idiopathic scoliosis treated with a Milwaukee brace and found that bracing did not significantly alter VC. On the other hand, Noble-Jamieson et al ${ }^{21}$ found a $22 \%$ fall in forced vital capacity (FVC) after the application of a brace in 16 children with scoliosis secondary to muscle weakness, and in a previous study we found an $18 \%$ fall in FVC in 33 children with thoracic idiopathic scoliosis treated with Boston and Milwaukee braces. ${ }^{9}$ In the present series of 13 children the mean reduction was $21.7 \%$ in FRC, $11.9 \%$ in TLC and $14.3 \%$ in FVC. The reduction in lung volumes was greatest at FRC. The likely cause of the reduction in lung volumes is the restriction of outward movement of the lower ribcage on inspiration in association with the displacement of abdominal contents into the lower chest by the rise in intra-abdominal pressure. This is supported by the twofold increase in intragastric pressure seen on application of the brace in both the sitting and the supine postures.

The effect of bracing on the pattern of respiratory muscle recruitment is substantial. In the unbraced subject the descent of the diaphragm on inspiration causes a rise in intra-abdominal pressure. This pressure rise is offset by being transmitted through the area of apposition to the lower ribcage, causing this to move outward. This outward movement increases thoracic cage volume, reduces intra-abdominal pressure, and allows the diaphragm to act optimally. ${ }^{22}$ In the braced subject the rise in intra-abdominal pressure will lengthen the diaphragm and improve its lengthtension characteristics. The area of apposition is also increased. As the lower ribcage is restricted, however, the further rise in gastric pressure during inspiration cannot be offset by the outward movement of the lower ribcage. Thus the diaphragm has to contract against a gastric pressure that is twice that in the unbraced state, implying an increase in diaphragmatic workload. In the face of limitation of lower ribcage expansion and increased diaphragmatic workload accessory muscles are recruited to offload the diaphragm. The seven children whose upper thoracic anteroposterior diameter was measured had a $95 \%$ increase in expansion in this region during inspiration when the brace was applied.

A substantial increase in the work of breathing during brace wearing is implied from the data, as there was a twofold increase in transdiaphragmatic swing when the brace was worn. A recent study $y^{23}$ has shown that if the abdomen is strapped during exercise Pdi increases but without any concomitant increase in the peak electromyographic activity of the diaphragm (Edi). When the ribcage was selectively restricted, however, there was a substantial increase in Edi without any significant changes in Pdi. Exercise endurance time was also reduced. Wearing a brace would result in a combination of these effects.

Many children when braced complain of reduced exercise tolerance. In view of our recent findings ${ }^{23}$ this is not surprising and is consistent with our view that there is a considerable increase in the work of breathing, which is likely to lead to respiratory muscle fatigue. During the period of bracing in both the sitting erect and the supine posture there was no increase in minute ventilation or respiratory rate despite the substantial increase in gastric and transdiaphragmatic pressures. This is consistent with the findings of Bradley et al, ${ }^{24}$ who found that it was the change in pleural pressure that influenced the sensation of inspiratory effort rather than changes in Pgas or Pdi. In our study pleural pressure (Poes) was unaltered by bracing. The twofold increase in Pdi implies a dramatic increase in the work of breathing, though this cannot be measured by standard techniques. In addition to measurement of pleural pressures the pressure developed under the brace would need to be measured.

The influence of bracing on the natural history of idiopathic scoliosis is currently being reviewed. ${ }^{4}$ At present, however, there is general agreement that bracing is indicated for the progressive curve in the 30 40 degree group. ${ }^{4}$ But we have clearly shown that bracing results in substantial changes in lung volumes and the pattern of respiratory muscle recruitment, and by implication an increase in respiratory muscle work. The long term effects of bracing on lung growth and intra-abdominal structures remain unknown.

In view of the doubts about the effect of idiopathic scoliosis on long term cardiorespiratory function, the influence of bracing on its natural history, the substantial functional effect of bracing on the respiratory system, and the unknown effects of the long term increase in intra-abdominal pressure, we suggest that the use of bracing in idiopathic scoliosis needs to be reviewed, particularly as school screening programmes are becoming more widespread. ${ }^{14}$

\section{References}

1 Bergofsky EH. Thoracic deformities. In: Roussos C, Macklem PT, eds. Thorax. Part E. New York: Dekker, 1985:941-78.

2 Dickson RA. Scoliosis in the community. Br Med $J$ 1983;286:615-8.

3 Dickson RA. Conservative treatment for idiopathic scoliosis. J Bone Joint Surg (BR) 1985;67B:176-81.

4 Edgar RA. To brace or not to brace [editorial]. $J$ Bone Joint Surg (BR) 1985;67B:173-4.

5 Blount WP, Schmidt AG, Keever ED, Leonard ET. The Milwaukee brace in the operative treatment of scoliosis. J Bone Joint Surg (Am) 1985;40A:511-25. 
6 Hall JE, Miller W, Shuman W, Stanish WA. A refined concept in the orthotic management of idiopathic scoliosis. Prosthet Orthot Int 1975;29:7-13.

7 Glucker T. Changes in vital capacity in scoliosis. J Bone Joint Surg (Am) 1962;44A:469-81.

8 Sevastikoglou JA, Linderholm H, Lindgren U. Effect of the Milwaukee brace on vital and ventilatory capacity of scoliotic patients. Acta Orthop Scand 1976;47:540-5.

9 Kennedy JD, Robertson CF, Olinsky A, Dickens DRV, Phelan PD. The pulmonary restrictive effect of bracing in mild idiopathic scoliosis. Thorax 1987;42:959-61.

10 Weng T, Levison H. Standards of pulmonary function in children. Am Rev Respir Dis 1969;99:879-94.

11 Hibbert ME, Lanigan A, Raven J, Phelan PD. Relation of armspan to height and the prediction of pulmonary function. Thorax 1988;43:657-9.

12 Onal E, Lopata M, Ginsburg AS, O'Connor TD. Diaphragmatic EMG and transdiaphragmatic pressure measurements with a single catheter. Am Rev Respir Dis 1981;124:563-5.

13 Beardsmore CS, Helms P, Stock J, Hatch DJ, Silverman M. Improved esophageal balloon technique for use in infants. J Appl Physiol 1980;49:735-42.

14 Baydur A, Behrakus PK, Zin WA, Jaeger M, Milic EJ. A simple method for assessing the validity of the esophageal balloon technique. Am Rev Respir Dis 1982; 126:788-91.

15 Morais T, Bechier M, Turcotte F. Age and sex-specific prevalence of scoliosis and the value of school screening programs. Am J Publ Health 1985;75:1377-80.

16 Miller JAA, Nachernson AL, Schultz AB. Effectiveness of braces in mild idiopathic scoliosis. Spine 1984; 9:632-5.

17 Cochran T, Nachernson A. Long term anatomic and functional changes in patients with adolescent idiopathic scoliosis treated with the Milwaukee brace. Spine 1985;10:127-33.

18 Evans JB, Kaelin A, Bancel P, Hall JE, Miller ME. The Boston bracing system for idiopathic scoliosis. Follow up results in 295 patients. Spine 1986;11:792-801.

19 Branthwaite MA. Cardiorespiratory consequences of idiopathic scoliosis. Br J Dis Chest 1986;80:360-9.

20 Blount WP, Mee JH. The Milwaukee brace. Baltimore: Williams and Wilkins, 1973.

21 Noble-Jamieson CM, Heckmatt JZ, Dubowitz V, Silverman $M$. Effects of posture and spinal bracing on respiratory function in neuromuscular disease. Arch Dis Child 1986;61:178-81.

22 Macklem PT. Inferring the actions of the respiratory muscles. In: Roussos C, Macklem PT, eds. Thorax. Part A. New York: Dekker, 1985:351-8.

23 Hussain SNA, Rabmovitch B, Macklem PT, Pardy RL. Effects of separate rib cage and abdominal restriction on exercise performance in normal humans. $J$ Appl Physiol 1985;58:2020-6.

24 Bradley TD, Chartrand DA, Fitting GW, Killian KJ, Grassino A. The relation of inspiratory effort sensation to fatiguing patterns of the diaphragm. Am Rev Respir Dis 1985;134:1119-24.

25 Berg U, Aaro S. Long-term effect of Boston brace treatment on renal function in patients with idiopathic scoliosis. Clin Orthop 1983;180:169-72. 